\title{
Mothers' behaviour contributes to suboptimal iodine status of family members: findings from an iodine-sufficient area
}

\author{
Pantea Nazeri ${ }^{1}$, Parvin Mirmiran ${ }^{1,2, *}$, Golaleh Asghari ${ }^{1}$, Nilufar Shiva ${ }^{3}$, \\ Yadollah Mehrabi ${ }^{4}$ and Fereidoun Azizi ${ }^{3}$ \\ 'Obesity Research Center, Research Institute for Endocrine Sciences, Shahid Beheshti University of Medical Sciences, \\ Tehran, Islamic Republic of Iran: ${ }^{2}$ Department of Clinical Nutrition and Dietetics, Faculty of Nutrition Sciences \\ and Food Technology, National Nutrition and Food Technology Research Institute, Shahid Beheshti University of \\ Medical Sciences, PO Box 19395-4741, Tehran, Islamic Republic of Iran: ${ }^{3}$ Endocrine Research Center, Research \\ Institute for Endocrine Sciences, Shahid Beheshti University of Medical Sciences, Tehran, Islamic Republic of Iran: \\ ${ }^{4}$ Department of Epidemiology, School of Public Health, Shahid Beheshti University of Medical Sciences, Tehran, \\ Islamic Republic of Iran
}

Submitted 22 April 2013: Final revision received 27 February 2014: Accepted 14 March 2014: First published online 24 April 2014

\begin{abstract}
Objective: Iodine deficiency still remains a major public health concern worldwide despite global progress in its elimination. The aims of the present study were to evaluate dietary iodine status in the mother and one adult member of each family and the association between mothers' knowledge, attitude and behaviour and the dietary iodine status of adult family members in Tehran.

Design: In this cross-sectional study, $24 \mathrm{~h}$ urinary iodine and $\mathrm{Na}$ concentrations and the iodine content of household salt were measured. Mothers' knowledge, attitude and behaviour were assessed using a questionnaire administered in faceto-face interviews.

Setting: Health-care centres from four distinct areas of Tehran.

Subjects: Mother-adult family member pairs aged $\geq 19$ years ( $n$ 290), enrolled through randomized cluster sampling.

Results: In mothers and adult family members, median $24 \mathrm{~h}$ urinary iodine concentration was 73 (interquartile range (IQR) 36-141) $\mu \mathrm{g} / \mathrm{l}$ and 70 (IQR 34-131) $\mu \mathrm{g} / \mathrm{l}$, dietary iodine intake was 143 (IQR 28-249) $\mu \mathrm{g} / \mathrm{d}$ and 130 (IQR 26-250) $\mu \mathrm{g} / \mathrm{d}$ and dietary salt intake was 8.0 (IQR 5.9-10.2) g/d and 7.5 (IQR 5.3-10.0) g/d, respectively. Significant correlations were observed between mothers' attitude and behaviour and the $24 \mathrm{~h}$ urinary iodine concentration, dietary iodine intake and iodine content of salt of adult family members. In multiple analysis, lower quartiles of salt iodine content and salt intake and inappropriate behaviour scores in mothers increased the risk of urinary iodine concentration $<100 \mu \mathrm{g} / 1$ in adult family members.

Conclusions: The present study showed that mothers' behaviour, but not knowledge and attitude, was among major contributors to the suboptimal dietary iodine status observed in adult family members.
\end{abstract}

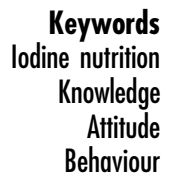

Iodine is a vital component of the thyroid hormones required for normal growth, development and tissue metabolism. Iodine deficiency can cause widespread detrimental effects including spontaneous abortion, stillbirth, congenital anomaly and prenatal mortality in fetuses and impaired mental function, decreased educability, reduced work productivity, goitre and hypothyroidism in adults ${ }^{(1-4)}$. Based on the WHO report, iodine deficiency still remains a major public health concern worldwide despite global progress in its elimination $^{(5)}$.

According to the WHO guidelines, an efficient way to estimate household iodine nutrition status is frequently assessment of urinary iodine concentration (UIC) in schoolchildren $^{(4)}$. However, some studies have revealed that UIC in schoolchildren is not an adequate criterion to estimate whole population iodine status ${ }^{(6-8)}$. The Islamic Republic of Iran is known as an area of iodine deficiency ${ }^{(9,10)}$. Production and nationwide consumption of iodized salt containing $40 \mathrm{ppm}$ iodine began in 1990 and became mandatory for household consumption by 1994. Since then, national surveys conducted every 5 years have shown sustainable elimination of iodine-deficiency disorders in schoolchildren. Although Iran was declared to be free of iodine deficiency in the year $2000^{(11)}$, results of the last national survey and a recent 
study conducted in Tehranian adults were indicative of decreases in median UIC to $<100 \mu \mathrm{g} / \mathrm{l}^{(6,12)}$. Moreover, the public health education campaign regarding iodized salt consumption was conducted through the earlier years of implementation of the universal salt iodization programme from 1989 to $1994^{(13)}$. After that there has been little or no public knowledge dissemination regarding iodized salt consumption via various mass media, measures that are essential to raise levels of public awareness and need to be prioritized in health policies.

On the other hand, it is well known that parents especially mothers' knowledge, attitude and behaviour have a great influence on the health conditions, quality of life and nutritional status of other members of the family, mainly their children ${ }^{(14-16)}$. Close correlations have been observed between parents and their children in dietary patterns and nutrient intakes ${ }^{(17-19)}$. However, only a few studies specifically address the effects of mothers' knowledge, attitude and behaviour on the health and nutrition status of other family members, i.e. adult members. With respect to family structure in Iran, where family members live very close to each other and are very dependent upon the core, and also the ultimate aim of the salt iodization programme in Iran which is the provision of adequate dietary iodine to all members of families not only schoolchildren, the present study was designed to explore, for the first time, the influence of mothers' knowledge, attitude and behaviour on the iodine nutrition status of adult family members and the relationship between iodine nutrition status of mothers and adult family members.

\section{Methods}

\section{Participant sampling}

The current cross-sectional study was conducted on the sample of a previous study of Tehranian adults in 2009, further details of which have been published elsewhere ${ }^{(6)}$. For selection of families, the health-care centres of eight districts from four distinct areas (i.e. the south, west, east and north) of Tehran were randomly selected. In each family, two adult members were selected for providing a $24 \mathrm{~h}$ urine sample; these included the mother who took responsibility for food preparation and one other adult member who was willing to participate in our study, was aged $\geq 19$ years, came from the same family (couple/ husband, or son or daughter, or others who lived in the joint family system) and who ate at least one meal with family members. After excluding incomplete urine samples, and pregnant and lactating mothers, 383 families including 639 adults (338 mothers and 301 one other adult members) remained for the analysis. Families that had only one adult member or provided only one $24 \mathrm{~h}$ urine sample were excluded. Hence, of 383 households, 290 families including 580 adults (290 mothers and 290 one other adult members) met the above-mentioned criteria. Personal information, medical history of thyroid diseases and hypertension, usage of medications and iodine-containing supplements were selfreported and documented using an interviewer-administered questionnaire. Households' per capita income in their region of residence was chosen as a proxy for socio-economic position (based on report of the Statistical Center of Iran), as evidence suggests that the three most common indicators of socio-economic status (SES) are education, income and occupation. Informed written consent was obtained from all participants and the Ethical Committee of the Research Institute for Endocrine Sciences, Shahid Beheshti University of Medical Sciences, Tehran, approved the study.

\section{Salt sample collection}

During the first home visit, a sample of two tablespoons of salt was collected from each of the 290 families. The samples were kept in lightproof, closed plastic cans and labelled with the code for each family.

\section{Urine collection}

At the first home visit, written instructions and 2.5 litre labelled plastic containers were given to the mother and one other adult member of each family, who were asked to collect all urine passed during a $24 \mathrm{~h}$ period, beginning on Friday (a weekend day in Iran), starting from the second morning urine and ending with the first urine passed the following morning.

At the second visit, on the following Saturday, all samples were collected and sent to the iodine laboratory of the Endocrine Research Center, Research Institute for Endocrine Sciences, Shahid Beheshti University of Medical Sciences, Tehran, the reference laboratory of the Eastern Mediterranean region; total volume was measured and urine was transferred into screw-topped labelled plastic vials. The aliquots were kept frozen until iodine, $\mathrm{Na}$ and creatinine concentrations were measured.

\section{Salt and iodine intake estimation}

Salt intake was estimated by $24 \mathrm{~h}$ urinary $\mathrm{Na}$ excretion $(1 \mathrm{~g} \text { salt }=17 \cdot 1 \mathrm{mmol} \mathrm{Na})^{(20-22)}$. In contrast to European countries where $80 \%$ of salt consumed is hidden ${ }^{(23)}$, in Iran a significant portion of salt intake comes from iodized salt, the main dietary iodine source which is used during cooking and as table salt. Hence iodine intake was estimated based on the amount of salt intake and the iodine content of salt.

\section{Mothers' knowledge, attitude and behaviour assessment}

To test knowledge, attitude and practices of mothers, an appropriate questionnaire was developed considering the following aspects of iodine nutrition status: the importance of iodine as an essential nutrient; the consequences of iodine-deficiency disorders; and purchase, consumption and preservation conditions of iodized salt. The general content and specific items of the questionnaire were 
initially derived from an intensive review of literature available in national and international sources by the main researcher. Irrelevant and unsuitable items were eliminated or changed based on experts' advice. This resulted in a questionnaire comprising twenty-four items that encompassed: (i) a Knowledge section with ten items; (ii) an Attitude section with eight items; and (iii) a Practice section with six items.

Validity of the questionnaire was confirmed by face and content validity. Face validity means that the instrument (i.e. questionnaire) covers the attribute it is intended to measure, on the face of it. Therefore, investigators seek experts or lay people to review the instrument for grammar, syntax, organization, appropriateness and confirmation that it appears to flow logically. Content validity indicates whether the items in the questionnaire complete the range of the attribute under study. After a researcher defines the construct of interest and its dimensions by searching the literature, seeking expert opinions, performing population sampling or through qualitative research, then a panel of content experts is asked to review the potential items and validate that they are appropriate indicators of the construct ${ }^{(24)}$. To ensure face validity, ten mothers completed the questionnaire, which assessed their knowledge, attitude and behaviour on the importance of iodine consumption in their daily lives. Also, they were asked to review the appropriateness and clarity of each item on the questionnaire. To assess content validity, an expert panel including ten specialists in nutrition, endocrinology, health education and sociology reviewed the potential items of the questionnaire. They were asked to comment on individual items in relation to their relevancy, clarity and necessity; items were modified slightly based on expert reviews. In addition, Cronbach's alpha was determined for internal consistency of the questionnaire (Cronbach's $\alpha=0.83$ ).

At the first home visit, mothers' knowledge, attitude and practice regarding iodine nutrition and iodized salt were assessed using a questionnaire administered by a skilled interviewer in a face-to-face manner. Knowledge questions were focused on the preservation conditions, time of salt addition during the cooking process and signs of iodinedeficiency disorders. Responses were 'yes', 'no' and 'do not know' options or three choices including 'true', 'false' and 'do not know'. The scoring system for each 'yes' and 'true' answer was 3 points, 'no' and 'false' answer scored 1 point, and 'do not know' was 2 points. The concept of the attitude questions was based on the importance of consumption of iodine and iodized salt. The answers were 'strongly disagree', 'disagree', 'have no idea', 'agree' and 'strongly agree', which were scored based on the Likert criteria from 1 point, as the undesirable, to 5 points, as the desirable attitude. Questions related to behaviour included the use of iodized salt, preservation conditions of iodized salt (e.g. exposure to light, humidity and storage in uncovered containers), time of salt addition during the cooking process and considerations during salt purchase. Each question was scored 1 point.
To assess the level of knowledge, attitude and practice regarding iodine nutrition and iodized salt, the scores in each section were calculated. Total score was 26 (range: 9-26) points for knowledge, 40 (range: 24-40) points for attitude, 6 (range: 0-6) points for practice and 68 (range: 38-68) points for the overall knowledge, attitude and practice questionnaire. Total score in each section was then categorized into three levels according to score tertiles. In each section of knowledge, attitude and practice, mothers who had scores below the lower, in the middle and above the higher tertiles were defined as having low, intermediate and high scores, respectively.

\section{Laboratory measurements}

Iodine concentration of salt samples was determined using the iodometric titration method with $1 \mathrm{ppm}$ sensitivity and $\mathrm{CV}$ of $1 \%{ }^{(25)}$, and the results are expressed in parts per million. The iodine concentration in urine samples was analysed using the Sandell-Kolthoff (acid digestion) reaction $^{(26)}$ and results are expressed as micrograms of iodine per litre of urine. The intra- and inter-assay CV were $9.6 \%$ and $10.4 \%$, respectively and the sensitivity was $2 \mu \mathrm{g} / \mathrm{l}$. Completion of $24 \mathrm{~h}$ urine sample collection was confirmed with creatinine concentration. Urine samples with creatinine levels below $500 \mathrm{mg} / \mathrm{d}$ were considered incomplete. Urinary creatinine was measured by the kinetic Jaffé method (Creatinine Colorimetric Kit; Pars Azmoun, Tehran, Iran). The assays were run using an autoanalyser (Vitalab Selectra-2; Vital Scientific NV, Dieren, the Netherlands). The inter-assay sensitivity and CV were $0 \cdot 2 \mathrm{mg} / \mathrm{dl}$ and $2 \cdot 1 \%$, respectively. $\mathrm{Na}$ excretion in $24 \mathrm{~h}$ urine collections was analysed by flame emission photometry (Corning 480 Flame Photometer; Dow Corning, Corning, NY, USA).

\section{Statistical analyses}

Means and standard deviations, medians and interquartile ranges (IQR), and numbers and proportions (\%) were computed according to continuous numerical and qualitative ordinal variables. The Wilcoxon and Kruskal-Wallis tests were used to compare non-parametric variables between mothers and adult family members, and among different age groups, education levels and SES categories. To identify influential factor(s) associated with UIC $<100 \mu \mathrm{g} / \mathrm{l}$ in adult family members, multiple logistic regression with the backward stepwise method was employed. The $\chi^{2}$ test at significance level $P<0.25$ was used to screen potential variable(s) to be included in the model. Statistical analyses were done using the statistical software package SPSS for Windows version $16 \cdot 0$, with $P<0.05$ being considered as significant.

\section{Results}

\section{General characteristics}

Two hundred and ninety mothers (mean age $44 \cdot 3$ (SD 11.2) years) and adult family members (mean age 41.5 (SD 15.0) 
Table 1 Basic characteristics (age, education level, medical history and use of iodine-containing supplements) of participants in the two groups, mothers and adult family members, Tehran, Iran

\begin{tabular}{|c|c|c|c|c|c|}
\hline \multirow[b]{2}{*}{ Characteristic } & \multicolumn{2}{|c|}{$\begin{array}{l}\text { Mothers } \\
(n \text { 290) }\end{array}$} & \multicolumn{2}{|c|}{$\begin{array}{l}\text { Adult family members } \\
(n 290)\end{array}$} & \multirow[b]{2}{*}{$P$ value } \\
\hline & $n$ & $\%$ & $n$ & $\%$ & \\
\hline Age (years) & & & & & $<0.001$ \\
\hline $19-24$ & 10 & 3.4 & 51 & $17 \cdot 6$ & \\
\hline $25-34$ & 46 & $15 \cdot 9$ & 53 & $18 \cdot 3$ & \\
\hline $35-49$ & 131 & $45 \cdot 2$ & 98 & 33.8 & \\
\hline$\geq 50$ & 103 & 35.5 & 88 & $30 \cdot 3$ & \\
\hline Education & & & & & $<0.001$ \\
\hline Illiterate & 24 & 8.3 & 9 & $3 \cdot 1$ & \\
\hline Primary & 127 & 43.8 & 86 & 29.7 & \\
\hline Secondary & 114 & $39 \cdot 3$ & 112 & 38.6 & \\
\hline University & 25 & 8.6 & 83 & $28 \cdot 6$ & \\
\hline Goitre & 11 & 3.8 & 2 & 0.7 & 0.005 \\
\hline Hypothyroidism & 24 & 8.3 & 3 & 1.0 & $<0.001$ \\
\hline Hyperthyroidism & 3 & 1.0 & 2 & $0 \cdot 7$ & 0.749 \\
\hline Hypertension & 40 & $13 \cdot 8$ & 28 & $9 \cdot 3$ & 0.044 \\
\hline Use of iodine-containing supplements & 8 & $2 \cdot 8$ & 1 & 0.3 & 0.011 \\
\hline
\end{tabular}

years) completed the study. Adult family members included 203 (70\%) husbands (mean age 47.7 (sD 12.3) years), fifty-two (18\%) daughters (mean age 25.4 (SD 6.1) years), twenty-nine (10\%) sons (mean age 24.3 (SD 4.4) years) and six ( $2 \%$ ) other individuals living with the family (mean age 53.1 (SD 18.2) years). The adults who were excluded did not differ significantly in basic characteristics from those included (data not shown). General characteristics of the participants in the two groups, mothers and adult family members, are shown in Table 1 . Significant differences in age, education, history of goitre, hypothyroidism, hyperthyroidism, hypertension and use of iodine-containing supplements were observed between the two groups.

\section{Urinary iodine concentration}

Median $24 \mathrm{~h}$ UIC in mothers and adult family members was 73 (IQR 36-141) $\mu \mathrm{g} / 1$ and 70 (IQR 34-131) $\mu \mathrm{g} / 1$, respectively $(P>0.05)$. Frequency distribution of UIC $<100 \mu \mathrm{g} / \mathrm{l}$ and UIC $<50 \mu \mathrm{g} / 1$ was $63 \%$ and $36 \%$ in mothers and $65 \%$ and $41 \%$ in adult family members, respectively. Values of median $24 \mathrm{~h}$ UIC in mothers with limited education and the oldest age group were lower than those in mothers with higher education levels and the youngest age group, respectively $(P<0.05)$; whereas no significant difference was observed for adult family members. Median $24 \mathrm{~h}$ UIC was lower in participants with low SES than in those with high SES: 40 (IQR 27-74) $\mu \mathrm{g} / \mathrm{l} v .95$ (IQR 50-161) $\mu \mathrm{g} / \mathrm{l}$ in mothers $(P<0.05)$ and 45 (IQR 27-86) $\mu \mathrm{g} / \mathrm{l} v .77$ (IQR 30-169) $\mu \mathrm{g} / \mathrm{l}$ in adults $(P<0 \cdot 05)$, respectively (Tables 2 and 3$)$.

\section{Dietary iodine intake}

Median dietary iodine intake in mothers and adult family members was 143 (IQR 28-249) $\mu \mathrm{g} / \mathrm{d}$ and 130 (IQR $26-250) \mu \mathrm{g} / \mathrm{d}$, respectively $(P>0 \cdot 05)$. Daily iodine intakes $>150 \mu \mathrm{g}$ (the RDA) were found in $47.0 \%$ and $44.9 \%$ of mothers and adult family members, respectively. We found significant differences in dietary iodine intake among mothers with different education levels and in different SES groups ( $P=0 \cdot 001$; Table 2$)$.

\section{Iodine content of bousebold salt}

Median iodine content of salt was 3 (IQR 2-20) ppm, 17 (IQR 2-30) ppm and 29 (IQR 19-36) ppm in low, middle and high SES, respectively $(P<0 \cdot 001)$. In mothers with the lowest education levels, the median iodine content of salt was significantly lower than in those with the highest education levels (6 ppm $v .32 \mathrm{ppm}$ ).

\section{Dietary salt intake}

Median daily salt intake in mothers and adult family members was 8.0 (IQR 5.9-10.2) g and 7.5 (IQR 5.3-10.0) $\mathrm{g}$, respectively $(P>0.05)$. The proportion of mothers and adult family members with daily salt intake $<5 \mathrm{~g}$ (recent WHO recommendation) was $16 \%$ and $22 \%$, respectively. Median salt intake among mothers in the youngest $v$. the oldest age group was $9.5 \mathrm{~g} / \mathrm{d}$ and $7.2 \mathrm{~g} / \mathrm{d}$, respectively, whereas corresponding values were $6.6 \mathrm{~g} / \mathrm{d}$ and $8.1 \mathrm{~g} / \mathrm{d}$ in adult family members. No significant differences in median salt intake according to education level and SES were found for both mothers and adult family members.

Mothers' knowledge, attitude and behaviour scores Scores obtained by mothers for knowledge, attitude and behaviour were as follows: for knowledge 34.5\%, 29.3\% and $35.5 \%$ of mothers had low, intermediate and high scores, respectively; corresponding values for attitude were $27.2 \%, 36.6 \%$ and $35.5 \%$; and for behaviour were $22.6 \%$, $63.9 \%$ and $13.5 \%$. There were significant differences in attitude and behaviour among different SES groups and education levels $(P<0 \cdot 001)$. In adult family members whose mothers had higher attitude and behaviour scores, the iodine content of salt, median $24 \mathrm{~h}$ UIC and dietary iodine 
Table 2 Median and interquartile range of $24 \mathrm{~h}$ urinary iodine concentration (UIC), salt intake and iodine intake, and the number percentage of mothers with $\mathrm{UIC}<100 \mu \mathrm{g} / \mathrm{l}$ and $\mathrm{UIC}<50 \mu \mathrm{g} / \mathrm{l}$, according to age group, education level, family socio-economic status (SES), and knowledge, attitude and behaviour categories, Tehran, Iran

\begin{tabular}{|c|c|c|c|c|c|c|c|c|c|c|c|}
\hline \multirow[b]{2}{*}{ Variable } & \multirow[b]{2}{*}{$n$} & \multicolumn{2}{|c|}{24 h UIC $(\mu \mathrm{g} / \mathrm{l})$} & \multicolumn{2}{|c|}{ Salt intake $(g / d)$} & \multicolumn{2}{|c|}{ lodine intake $(\mu \mathrm{g} / \mathrm{d})$} & \multicolumn{2}{|c|}{$\mathrm{UIC}<100 \mu \mathrm{g} / \mathrm{l}$} & \multicolumn{2}{|c|}{$\mathrm{UIC}<50 \mu \mathrm{g} / \mathrm{l}$} \\
\hline & & Median & IQR & Median & IQR & Median & IQR & $n$ & $\%$ & $n$ & $\%$ \\
\hline $\begin{array}{l}\text { All mothers } \\
\text { Age (years) }\end{array}$ & 290 & $73 \cdot 0$ & $35 \cdot 5-140 \cdot 5$ & 8.0 & $5 \cdot 9-10 \cdot 2$ & $142 \cdot 7$ & $28 \cdot 1-249 \cdot 3$ & 182 & $62 \cdot 8$ & 105 & $36 \cdot 2$ \\
\hline $19-24$ & 10 & $84 \cdot 5^{\star}$ & $40 \cdot 0-155 \cdot 0$ & 9.5 & $8 \cdot 3-11 \cdot 8$ & $120 \cdot 2$ & $24.5-238.5$ & 7 & $70 \cdot 0$ & 4 & $40 \cdot 0$ \\
\hline $25-34$ & 46 & $80 \cdot 0$ & $44 \cdot 0-164 \cdot 9$ & 7.5 & $5 \cdot 8-10.5$ & 134.9 & $27 \cdot 0-233 \cdot 6$ & 26 & 56.5 & 16 & 34.8 \\
\hline $35-49$ & 131 & $85 \cdot 0$ & $47 \cdot 0-151 \cdot 0$ & $8 \cdot 3$ & $6 \cdot 0-10 \cdot 3$ & $159 \cdot 3$ & $30.8-291.9$ & 77 & $58 \cdot 8$ & 38 & $29 \cdot 0$ \\
\hline$\geq 50$ & 103 & $54 \cdot 0$ & $31 \cdot 5-109 \cdot 0$ & $7 \cdot 2$ & $5 \cdot 7-9 \cdot 6$ & $110 \cdot 9$ & $28 \cdot 5-212 \cdot 6$ & 72 & 69.9 & 47 & $45 \cdot 6$ \\
\hline \multicolumn{12}{|l|}{ Education level } \\
\hline Illiterate & 24 & $37 \cdot 0^{\star}$ & $28.5-54.5$ & $7 \cdot 6$ & $6 \cdot 1-9 \cdot 6$ & $32 \cdot 8^{\star}$ & $10 \cdot 3-148 \cdot 6$ & $22^{*}$ & 91.7 & $17^{\star}$ & $70 \cdot 8$ \\
\hline Primary & 127 & $62 \cdot 2$ & $32 \cdot 2-112 \cdot 0$ & 8.4 & $5 \cdot 9-10 \cdot 6$ & 117.5 & $20 \cdot 5-226 \cdot 0$ & 85 & 66.9 & 53 & 41.7 \\
\hline Secondary & 114 & $87 \cdot 0$ & $49 \cdot 0-160 \cdot 0$ & 7.9 & $5.8-9.9$ & $164 \cdot 0$ & $61 \cdot 4-296 \cdot 2$ & 63 & $55 \cdot 3$ & 30 & $26 \cdot 3$ \\
\hline Higher & 25 & $127 \cdot 0$ & $59 \cdot 0-176 \cdot 1$ & $8 \cdot 1$ & $5 \cdot 8-9 \cdot 0$ & $200 \cdot 3$ & $93.5-324 \cdot 4$ & 12 & 48.0 & 5 & $20 \cdot 0$ \\
\hline \multicolumn{12}{|l|}{ Family SES } \\
\hline High & 123 & $95 \cdot 0$ & $49 \cdot 5-161 \cdot 4$ & $7 \cdot 7$ & $5 \cdot 7-9 \cdot 6$ & $205 \cdot 2$ & $122 \cdot 7-299 \cdot 6$ & 62 & 50.4 & 32 & $26 \cdot 0$ \\
\hline Middle & 105 & $72 \cdot 0$ & $40 \cdot 0-142 \cdot 0$ & $8 \cdot 1$ & $5.9-9.9$ & $94 \cdot 1$ & $14 \cdot 7-218 \cdot 4$ & 67 & 63.8 & 34 & $32 \cdot 4$ \\
\hline Low & 62 & $39.5^{\star}$ & $27 \cdot 0-74 \cdot 0$ & 8.4 & $6 \cdot 2-11 \cdot 8$ & $32.9^{\star}$ & $15 \cdot 4-160 \cdot 0$ & $53^{\star}$ & 85.5 & $39^{*}$ & 62.9 \\
\hline \multicolumn{12}{|l|}{ Knowledge score } \\
\hline High & 103 & 68.5 & $37 \cdot 0-138$ & $8 \cdot 2$ & $6 \cdot 4-10 \cdot 4$ & $152 \cdot 2$ & $30 \cdot 4-264 \cdot 0$ & 69 & $67 \cdot 0$ & 37 & 35.9 \\
\hline Intermediate & 85 & $70 \cdot 0$ & $36 \cdot 0-136 \cdot 0$ & $7 \cdot 1$ & $5 \cdot 8-9.6$ & $147 \cdot 3$ & $31 \cdot 2-229 \cdot 6$ & 51 & $60 \cdot 0$ & 29 & $34 \cdot 1$ \\
\hline Low & 100 & $76 \cdot 5$ & $33 \cdot 0-144 \cdot 4$ & $7 \cdot 7$ & $5 \cdot 6-9.6$ & $127 \cdot 7$ & $24 \cdot 7-233 \cdot 2$ & 62 & $62 \cdot 0$ & 39 & 39.0 \\
\hline \multicolumn{12}{|l|}{ Attitude score } \\
\hline High & 103 & $87 \cdot 0$ & $47 \cdot 0-152 \cdot 5$ & 7.5 & $5 \cdot 7-9 \cdot 3$ & $168 \cdot 1$ & $53 \cdot 3-288 \cdot 0$ & 58 & $56 \cdot 3$ & 28 & $27 \cdot 2$ \\
\hline Intermediate & 106 & $72 \cdot 0$ & $34.0-144 \cdot 4$ & $8 \cdot 1$ & $6 \cdot 1-10 \cdot 2$ & $148 \cdot 7$ & $60 \cdot 8-232 \cdot 6$ & 67 & 63.2 & 38 & 35.8 \\
\hline Low & 76 & $54 \cdot 0^{*}$ & $30 \cdot 0-106 \cdot 4$ & 8.9 & $5 \cdot 8-10 \cdot 5$ & $39 \cdot 0^{\star}$ & $15 \cdot 4-209 \cdot 0$ & $57^{\star}$ & $72 \cdot 2$ & $39^{*}$ & 49.4 \\
\hline \multicolumn{12}{|l|}{ Behaviour score } \\
\hline High & 39 & $112 \cdot 0$ & $59 \cdot 9-178 \cdot 4$ & $8 \cdot 1$ & $6.5-9.7$ & $199 \cdot 8$ & $97.5-285.9$ & 16 & 41.0 & 8 & 20.5 \\
\hline Intermediate & 184 & 78.0 & $41.5-144.0$ & 7.5 & $5 \cdot 7-9 \cdot 6$ & 157.4 & $36 \cdot 2-251 \cdot 6$ & 115 & 62.5 & 60 & 32.6 \\
\hline Low & 65 & $46 \cdot 0^{\star}$ & $27 \cdot 0-87 \cdot 0$ & 9.2 & $6 \cdot 0-11 \cdot 0$ & $42 \cdot 8^{\star}$ & $16 \cdot 3-163 \cdot 1$ & $51^{\star}$ & 78.5 & $37^{\star}$ & $56 \cdot 9$ \\
\hline
\end{tabular}

${ }^{*} P<0.05$.

Table 3 Median and interquartile range of $24 \mathrm{~h}$ urinary iodine concentration (UIC), salt intake and iodine intake, and the number and percentage of adult family members with $\mathrm{UIC}<100 \mu \mathrm{g} / \mathrm{l}$ and $\mathrm{UIC}<50 \mu \mathrm{g} / \mathrm{l}$, according to age group, education level, family socio-economic status (SES), and mothers' knowledge, attitude and behaviour categories, Tehran, Iran

\begin{tabular}{|c|c|c|c|c|c|c|c|c|c|c|c|}
\hline \multirow[b]{2}{*}{ Variable } & \multirow[b]{2}{*}{$n$} & \multicolumn{2}{|c|}{24 h UIC ( $\mu \mathrm{g} / \mathrm{l})$} & \multicolumn{2}{|c|}{ Salt intake $(g / d)$} & \multicolumn{2}{|c|}{ lodine intake $(\mu \mathrm{g} / \mathrm{d})$} & \multicolumn{2}{|c|}{$\mathrm{UIC}<100 \mu \mathrm{g} / \mathrm{l}$} & \multicolumn{2}{|c|}{$\mathrm{UIC}<50 \mu \mathrm{g} / \mathrm{l}$} \\
\hline & & Median & IQR & Median & IQR & Median & IQR & $n$ & $\%$ & $n$ & $\%$ \\
\hline $\begin{array}{l}\text { All adult family members } \\
\text { Age (years) }\end{array}$ & 290 & $70 \cdot 0$ & $34.0-131 \cdot 0$ & $7 \cdot 5$ & $5 \cdot 3-10 \cdot 0$ & 129.5 & $25 \cdot 6-249 \cdot 5$ & 187 & 64.5 & 118 & $40 \cdot 7$ \\
\hline $19-24$ & 51 & $79 \cdot 0$ & $42 \cdot 0-146 \cdot 1$ & $6 \cdot 6^{*}$ & $4 \cdot 8-8 \cdot 3$ & $135 \cdot 0$ & $16 \cdot 1-228 \cdot 2$ & 32 & $62 \cdot 7$ & 18 & 35.3 \\
\hline $25-34$ & 53 & 69.0 & $32 \cdot 0-136.5$ & $7 \cdot 6$ & $5 \cdot 3-10 \cdot 2$ & 134.6 & $25 \cdot 6-259 \cdot 0$ & 32 & 60.4 & 20 & 37.7 \\
\hline $35-49$ & 98 & $77 \cdot 2$ & $38.0-131.0$ & $7 \cdot 3$ & $5 \cdot 4-9 \cdot 7$ & 113.0 & $119 \cdot 0-224 \cdot 1$ & 59 & $60 \cdot 2$ & 37 & 37.8 \\
\hline$\geq 50$ & 88 & 53.6 & $28 \cdot 6-103 \cdot 9$ & $8 \cdot 1$ & $5 \cdot 5-10 \cdot 6$ & $156 \cdot 4$ & $43 \cdot 6-275 \cdot 5$ & 64 & $72 \cdot 7$ & 43 & 48.9 \\
\hline \multicolumn{12}{|l|}{ Education level } \\
\hline Illiterate & 9 & $86.0^{*}$ & $45 \cdot 0-101 \cdot 0$ & $6 \cdot 1$ & $5 \cdot 1-10 \cdot 0$ & $154 \cdot 0^{\star}$ & $75 \cdot 4-238.5$ & $6^{\star}$ & $66 \cdot 7$ & $3^{*}$ & 33.3 \\
\hline Primary & 86 & 55.6 & $34.0-103.8$ & $7 \cdot 8$ & $5.4-11.0$ & 41.3 & $12 \cdot 4-198 \cdot 8$ & 63 & $73 \cdot 3$ & 41 & $47 \cdot 7$ \\
\hline Secondary & 112 & 71.4 & $28 \cdot 1-135 \cdot 0$ & $7 \cdot 3$ & $5 \cdot 1-9.4$ & 144.7 & $38 \cdot 6-244.5$ & 74 & $66 \cdot 1$ & 46 & 41.1 \\
\hline Higher & 83 & 90.0 & $44.0-155 \cdot 0$ & 7.4 & $5 \cdot 3-10 \cdot 2$ & 158.0 & $55 \cdot 0-299 \cdot 7$ & 44 & 53.0 & 28 & 33.7 \\
\hline \multicolumn{12}{|l|}{ Family SES } \\
\hline High & 123 & 76.5 & $29 \cdot 6-168 \cdot 8$ & 7.5 & $5.4-10.4$ & 177.5 & $99.5-326.5$ & 72 & 58.5 & 49 & 39.8 \\
\hline Middle & 105 & 83.5 & $42 \cdot 5-122 \cdot 5$ & 6.9 & $5 \cdot 3-9.6$ & $106 \cdot 7$ & $13 \cdot 0-235 \cdot 8$ & 64 & $61 \cdot 0$ & 35 & 33.3 \\
\hline Low & 62 & $45 \cdot 0^{*}$ & $27 \cdot 0-86 \cdot 0$ & $7 \cdot 7$ & $5 \cdot 0-9 \cdot 4$ & $27 \cdot 2^{\star}$ & $13 \cdot 8-134 \cdot 9$ & $51^{*}$ & $82 \cdot 3$ & $34^{*}$ & 54.8 \\
\hline \multicolumn{12}{|l|}{ Mothers' knowledge score } \\
\hline High & 103 & 71.0 & $33 \cdot 6-127 \cdot 0$ & $7 \cdot 1$ & $5 \cdot 2-9.5$ & 129.5 & $25 \cdot 1-261 \cdot 5$ & 68 & $66 \cdot 0$ & 40 & 38.8 \\
\hline Intermediate & 85 & 67.5 & $32 \cdot 0-131 \cdot 4$ & 7.9 & $5.5-11.0$ & $145 \cdot 9$ & $25 \cdot 2-254 \cdot 8$ & 56 & 65.9 & 37 & 43.5 \\
\hline Low & 100 & 73.8 & $35 \cdot 5-127 \cdot 0$ & $6 \cdot 7$ & $5 \cdot 1-9 \cdot 7$ & $101 \cdot 0$ & $26 \cdot 7-219 \cdot 8$ & 63 & 63.0 & 41 & 41.0 \\
\hline \multicolumn{12}{|l|}{ Mothers' attitude score } \\
\hline High & 103 & 88.5 & $48 \cdot 0-137.1$ & $6 \cdot 7$ & $5 \cdot 2-10 \cdot 2$ & $146 \cdot 4$ & $48 \cdot 1-311 \cdot 5$ & 59 & $57 \cdot 3$ & 31 & 30.1 \\
\hline Intermediate & 106 & 75.5 & $31 \cdot 0-155 \cdot 0$ & 7.5 & $5.4-9.5$ & 154.5 & $28 \cdot 0-259 \cdot 0$ & 63 & 59.4 & 44 & 41.5 \\
\hline Low & 76 & $43 \cdot 0^{*}$ & $27 \cdot 0-87 \cdot 2$ & $7 \cdot 6$ & $5 \cdot 0-9 \cdot 9$ & $43 \cdot 6$ & $15 \cdot 3-156 \cdot 4^{*}$ & $65^{\star}$ & $82 \cdot 3$ & $43^{*}$ & 54.4 \\
\hline \multicolumn{12}{|l|}{ Mothers' behaviour score } \\
\hline High & 39 & $131 \cdot 8$ & $49 \cdot 5-174 \cdot 6$ & 7.4 & $5 \cdot 6-9 \cdot 1$ & $187 \cdot 0$ & $82 \cdot 4-252 \cdot 4$ & 19 & $48 \cdot 7$ & 11 & 28.2 \\
\hline Intermediate & 184 & $75 \cdot 9$ & $34.0-131.0$ & $7 \cdot 1$ & $5 \cdot 3-9 \cdot 7$ & 143.9 & $32 \cdot 8-267 \cdot 1$ & 112 & $60 \cdot 9$ & 70 & 38.0 \\
\hline Low & 65 & $44 \cdot 5^{\star}$ & $26.5-83.5$ & $7 \cdot 6$ & $5 \cdot 1-10 \cdot 2$ & $34.4^{\star}$ & $15 \cdot 9-140 \cdot 0$ & $56^{\star}$ & $86 \cdot 2$ & $37^{*}$ & 56.9 \\
\hline
\end{tabular}

${ }^{\star} P<0.05$ 
Table 4 Factors associated with UIC $<100 \mu \mathrm{g} / \mathrm{l}$ in adult family members by univariate and multiple logistic regression analyses, Tehran, Iran

\begin{tabular}{|c|c|c|c|c|c|c|}
\hline \multirow[b]{2}{*}{ Variable } & \multicolumn{2}{|c|}{ Univariate analysis } & \multirow[b]{2}{*}{$P$ value } & \multicolumn{2}{|c|}{ Multiple analysis $†$} & \multirow[b]{2}{*}{$P$ value } \\
\hline & OR & $95 \% \mathrm{Cl}$ & & OR & $95 \% \mathrm{Cl}$ & \\
\hline \multicolumn{7}{|l|}{ Age (years) } \\
\hline $19-24$ & 1.00 & Reference & - & - & - & - \\
\hline $25-34$ & 0.90 & $0.41,1.99$ & 0.804 & - & - & - \\
\hline $34-49$ & 0.89 & $0.44,1.80$ & 0.763 & - & - & - \\
\hline$\geq 50$ & 1.58 & $0.75,3.30$ & 0.221 & - & - & - \\
\hline \multicolumn{7}{|l|}{ Education level } \\
\hline University & 1.00 & Reference & - & - & - & - \\
\hline Secondary & 1.72 & $0.96,3.08$ & 0.066 & - & - & - \\
\hline Primary & 2.42 & $1.27,4.61$ & 0.007 & - & - & - \\
\hline Illiterate & 1.77 & $0.41,7.56$ & 0.439 & - & - & - \\
\hline \multicolumn{7}{|l|}{ Salt intake (g/d) } \\
\hline Q4 $(\geq 9.9)$ & 1.00 & Reference & - & 1.00 & Reference & - \\
\hline Q3 (7.7-9.9) & 1.45 & $0.71,2.95$ & 0.302 & 1.53 & $0.66,3.53$ & 0.312 \\
\hline Q2 (5.6-7.7) & 1.99 & $1.00,3.69$ & 0.050 & 2.51 & $1 \cdot 13,5 \cdot 55$ & 0.023 \\
\hline Q1 $(\leq 5 \cdot 6)$ & 2.06 & $1.08,3.93$ & 0.027 & $2 \cdot 38$ & $1 \cdot 13,5 \cdot 00$ & 0.022 \\
\hline \multicolumn{7}{|c|}{ lodine content of salt (ppm) } \\
\hline Q4 ( $\geq 31.7)$ & 1.00 & Reference & - & 1.00 & Reference & - \\
\hline Q3 $(21 \cdot 2-31 \cdot 7)$ & 1.98 & $1 \cdot 01,3 \cdot 86$ & 0.045 & 2.02 & $0.97,4 \cdot 20$ & 0.059 \\
\hline Q2 (3.2-21.2) & 4.99 & $2.39,10.41$ & $<0.001$ & 4.09 & $1 \cdot 80,6 \cdot 31$ & 0.001 \\
\hline Q1 ( $\leq 3 \cdot 2)$ & 7.91 & $3.69,16.94$ & $<0.001$ & 7.05 & $2 \cdot 89,17 \cdot 21$ & $<0.001$ \\
\hline \multicolumn{7}{|l|}{ Family SES } \\
\hline High & 1.00 & Reference & - & 1.00 & Reference & - \\
\hline Middle & $1 \cdot 10$ & $1.56,6.90$ & 0.711 & 0.53 & $0.28,1.05$ & 0.069 \\
\hline Low & 3.26 & $0.65,1.88$ & 0.002 & 1.15 & $0.44,2.97$ & 0.767 \\
\hline \multicolumn{7}{|c|}{ Mothers' knowledge score } \\
\hline High & 1.00 & Reference & - & - & - & - \\
\hline Intermediate & 0.99 & $0.54,1.82$ & 0.984 & - & - & - \\
\hline Low & 0.87 & $0.49,1.55$ & 0.653 & - & - & - \\
\hline \multicolumn{7}{|c|}{ Mothers' attitude score } \\
\hline High & 1.00 & Reference & - & - & - & - \\
\hline Intermediate & 1.09 & $0.63,1.89$ & 0.752 & - & - & - \\
\hline Low & 3.46 & $1.72,6.95$ & $<0.001$ & - & - & - \\
\hline \multicolumn{7}{|c|}{ Mothers' behaviour score } \\
\hline High & 1.00 & Reference & - & 1.00 & Reference & - \\
\hline Intermediate & 1.63 & $0.81,3.27$ & 0.164 & 1.53 & $0.71,3.30$ & 0.274 \\
\hline Low & 6.55 & $2 \cdot 55,16.82$ & $<0.001$ & 4.81 & $1 \cdot 66,13 \cdot 88$ & 0.004 \\
\hline \multicolumn{7}{|c|}{ Mothers' age (years) } \\
\hline $19-24$ & 1.00 & Reference & - & 1.00 & Reference & - \\
\hline $25-34$ & 1.87 & $0.47,7.45$ & 0.372 & $2 \cdot 60$ & $0.53,12 \cdot 64$ & 0.236 \\
\hline $34-49$ & 1.42 & $0.39,5 \cdot 16$ & 0.589 & $2 \cdot 20$ & $0.48,9.96$ & 0.304 \\
\hline$\geq 50$ & $2 \cdot 67$ & $0.72,9.96$ & $0 \cdot 141$ & 4.33 & $0.92,20 \cdot 24$ & 0.063 \\
\hline \multicolumn{7}{|c|}{ Mothers' education level } \\
\hline University & 1.00 & Reference & - & - & - & - \\
\hline Secondary & 1.04 & $0.43,2.49$ & 0.926 & - & - & - \\
\hline Primary & 1.77 & $0.73,4.25$ & 0.200 & - & - & - \\
\hline Illiterate & 3.92 & $1.03,14.89$ & 0.044 & - & - & - \\
\hline
\end{tabular}

UIC, urinary iodine concentration; Q, quartile; SES, socio-economic status. †Multiple analysis was run with the backward stepwise method.

intake were significantly higher than in adult family members whose mothers had lower scores for attitude and behaviour $(P<0.05)$. Significant correlations were observed between the median $24 \mathrm{~h}$ UIC, dietary iodine intake and salt iodine content of adult family members and mothers' attitude $(r=0.17, P=0.003 ; r=0.20, P=0.001 ; r=0.22, P<0.001$, respectively) and behaviour $(r=0.15, P=0.008 ; r=0.24$, $P<0.001 ; r=0.22, P<0.001$, respectively). There were no significant associations between mothers' knowledge, attitude and behaviour and adult family members' dietary salt intake.

The results of univariate and multiple logistic regression analyses are shown in Table 4 . In multiple analysis, lower quartiles of salt iodine content and salt intake increased the risk of UIC $<100 \mu \mathrm{g} / \mathrm{l}$ as compared with higher quartiles. Inappropriate behaviour scores in mothers increased the risk of UIC $<100 \mu \mathrm{g} / 1$ in adult family members as compared with higher scores. There was no statistically significant association between UIC $<100 \mu \mathrm{g} / \mathrm{l}$ in adult family members and mothers' age and family SES.

\section{Discussion}

The current research indicated that dietary iodine status among Tehranian mothers and adult family members was 
marginally suboptimal and was significantly correlated. Mothers' behaviour, but not knowledge and attitude, had a significant effect on the dietary iodine status of adult members of the family. The adult family member whose mother had higher behaviour score had better iodine intake and iodine nutritional status and consumed more salt with optimal iodine content.

Lack of nutritional knowledge is parallel to individuals' dietary iodine insufficiency. In various countries such as India, Nigeria, South Africa, Kazakhstan and Australia, a low level of knowledge is one of the most important obstacles hindering successful elimination of iodine deficiency ${ }^{(27-30)}$. However, similar to our previous study on the association between iodine nutrition status and knowledge, attitude and behaviour in Tehranian women ${ }^{(31)}$, in the current study no association was found between mothers' knowledge and attitude and iodine nutrition status in adult family members. This contradiction may be attributable to the impact of different factors on nutrition knowledge, i.e. age, education, socio-economic position and occupation ${ }^{(32)}$. Moreover, high nutritional knowledge and positive attitude do not necessarily lead to behavioural outcome and dietary changes, as indicated in our study ${ }^{(33)}$.

Two common ideas exist about the association between attitude and behaviour. As the primary idea, attitude more than knowledge motivates behaviour and differences in behaviour are reflected by differences in attitude. The second idea demonstrates that educational background and overall SES rather than attitude influence health and health-related behaviour ${ }^{(34-36)}$. Our findings indicated that despite generally having positive attitude towards the importance of iodine and iodized salt, vulnerability to iodine deficiency and inadequate dietary iodine intake, low iodine content of salt and high salt intake were observed more in lower SES groups than in those with higher SES. These results support the second idea that as compared with those of a higher socio-economic background, individuals with lower socio-economic levels have a less healthy dietary pattern, consume more foods with high energy density and lower nutrient density, and fewer fruits and vegetables and more high-fat and high-salt snacks $^{(37,38)}$.

Familial correlation in dietary intakes has been found especially between parents and their children ${ }^{(17-19,39)}$. However in spite of close correlation in families such as Iranian family members observed here, as compared with younger children the impact of parental roles might be diminished in older children and adolescents due to their increasing independence as they grow older; consequently, dissimilarities in dietary intakes could be expected between parents and other adult members of the family ${ }^{(15)}$. In a study by Ategbo et al., there was no correlation in iodine status between schoolchildren and pregnant mothers from the same household ${ }^{(40)}$. For example, in families using salt with optimal iodine content, children and pregnant mothers had median UIC of $171 \mu \mathrm{g} / \mathrm{l}$ and $126 \mu \mathrm{g} / \mathrm{l}$, indicating iodine sufficiency and deficiency, respectively; a difference which, of course, can be explained by the physiological status of pregnant women, who need an additional dietary iodine intake. However, in agreement with other studies conducted among parents ${ }^{(18,19)}$, the findings of the present study confirm this similarity in patterns of dietary iodine and salt intakes between mothers and adult members of the family.

Different factors other than knowledge, attitude and behaviour have an impact on iodine nutrition status. As seen in a French study conducted on an adult population, dietary iodine intake is influenced by age, education, energy intake and smoking ${ }^{(41)}$. The present study revealed that iodized salt, used during cooking and as table salt, is the main dietary iodine source providing almost all the iodine intake in Iran, where due to the low iodine content of its soil, many locally grown plants and animal foods have iodine concentrations too low to serve as constant contributors to the iodine supply ${ }^{(11,42)}$. Furthermore, as stated in our previous study ${ }^{(6)}$, the illegal production and distribution of less expensive or inadequately iodized brands of salt is another major destabilizing factor in sufficient dietary iodine intake. Our findings that individuals with lower daily salt intake and iodine content of salt were more susceptible to iodine deficiency are consistent with WHO reports ${ }^{(4,23,43)}$. In addition, no associations were observed between salt intake and mothers' knowledge, attitude and behaviour regarding iodine and iodized salt, which can be explained by the fact that salt intake is strongly determined by environmental issues such as cultural factors and palatability ${ }^{(44)}$. Also, taste preference and satisfaction rather than health aspects are a major contributor in salt intake, data confirmed in our study ${ }^{(45)}$.

The present study has a few potential limitations that need to be considered. First, we could not measure the dietary iodine intake through iodine content of foodstuffs, although iodized salt is the main dietary of iodine source in Iran. Second, iodine concentration in a $24 \mathrm{~h}$ urine sample is considered a gold standard for determination of dietary iodine intake. Yet, a single $24 \mathrm{~h}$ urine sample is an inappropriate indicator of habitual iodine intake, because of variation in daily dietary iodine intakes ${ }^{(46)}$. Third, causality relationships cannot be established due to the cross-sectional design of the study.

\section{Conclusion}

Marginally suboptimal iodine status was observed in both mothers and adult family members of the Tehranian families studied. Furthermore, there was a significant correlation between UIC of mothers and adult members of the family. It seems that maternal behaviour has a significant effect not only on children, but also on other adult members of the family. Our study findings emphasize the importance of continuous public education regarding iodine nutrition in areas that have iodine sufficiency, 
following effective universal salt iodization. Appropriate social marketing and encouraging the willing cooperation of families, in particular mothers, could guarantee effective, long-lasting adequate iodine nutrition in the community.

\section{Acknowledgements}

Financial support: This study was supported by financial grants from the Research Institute for Endocrine Sciences, Shahid Beheshti University of Medical Sciences and the National Nutrition and Food Technology Research Institute, Faculty of Nutrition and Food Technology, Shahid Beheshti University of Medical Sciences, Tehran, Islamic Republic of Iran. Both funders had no role in the design, analysis or writing of this article. Conflict of interest: None. Authorship: P.N. contributed to the design, data analysis and writing of the manuscript; P.M. contributed to the design of the study and writing, reading and final approval of the manuscript; G.A. contributed to the design of the study and writing of the manuscript; N.S. contributed to the design of the study and writing of the manuscript; Y.M. contributed to the statistical analysis and writing of the manuscript; F.A. contributed to the design of the study and writing, reading and final approval of the manuscript. Ethics of human subject participation: Informed written consent was obtained from all participants and the Ethical Committee of the Research Institute for Endocrine Sciences approved this study.

\section{References}

1. Dunn JT (2006) Iodine. In Modern Nutrition in Health and Disease, pp. 300-311 [ME Shils, M Shike, CA Ross et al., editors]. Philadelphia, PA: Lippincott Williams \& Wilkins.

2. Zimmermann MB (2012) The effects of iodine deficiency in pregnancy and infancy. Paediatr Perinat Epidemiol 26, Suppl. 1, 108-117.

3. Pearce EN, Andersson M \& Zimmermann MB (2013) Global iodine nutrition: where do we stand in 2013? Thyroid $\mathbf{2 3}$, 523-528.

4. World Health Organization (2004) Iodine Status Worldwide. WHO Global Database on Iodine Deficiency. Geneva: WHO; available at http://whqlibdoc.who.int/publications/ 2004/9241592001.pdf

5. De Benoist B, McLean E, Andersson M et al. (2008) Iodine deficiency in 2007: global progress since 2003. Food Nutr Bull 29, 195-202.

6. Nazeri P, Mirmiran P, Mehrabi Y et al. (2010) Evaluation of iodine nutritional status in Tehran, Iran: iodine deficiency within iodine sufficiency. Thyroid 20, 1399-1406.

7. Rego-Iraeta A, Perez-Fdez R, Cadarso-Suarez C et al. (2007) Iodine nutrition in the adult population of Galicia (Spain). Thyroid 17, 161-167.

8. Soriguer F, Garcia-Fuentes E, Gutierrez-Repiso C et al. (2012) Iodine intake in the adult population. Di@bet.es study. Clin Nutr 31, 882-888.

9. Emami A, Shahbazi H, Sabzevari M et al. (1969) Goiter in Iran. Am J Clin Nutr 22, 1584-1588.

10. Azizi F, Kimiagar M, Nafarabadi M et al. (1990) Current status of iodine deficiency disorders in the Islamic Republic of Iran. EMR Health Service J 8, 23-27.
11. Azizi F, Sheikholeslam R, Hedayati M et al. (2002) Sustainable control of iodine deficiency in Iran: beneficial results of the implementation of the mandatory law on salt iodization. J Endocrinol Invest 25, 409-413.

12. Delshad H, Amouzegar A, Mirmiran P et al. (2012) Eighteen years of continuously sustained elimination of iodine deficiency in the Islamic Republic of Iran: the vitality of periodic monitoring. Thyroid 22, 415-421.

13. Sheikholeslam R (1996) Progress towards elimination of IDD in the Islamic Republic of Iran: a KAP survey of iodized salt consumption. East Mediterr Health J 2, 236-242.

14. Vereecken C \& Maes L (2010) Young children's dietary habits and associations with the mothers' nutritional knowledge and attitudes. Appetite 54, 44-51.

15. Vereecken C, Haerens L, De Bourdeaudhuij I et al. (2010) The relationship between children's home food environment and dietary patterns in childhood and adolescence. Public Health Nutr 13, 1729-1735.

16. Tahirovic H \& Toromanovic A (2010) Glycemic control in diabetic children: role of mother's knowledge and socioeconomic status. Eur J Pediatr 169, 961-964.

17. Ovaskainen ML, Nevalainen J, Uusitalo L et al. (2009) Some similarities in dietary clusters of pre-school children and their mothers. Br J Nutr 102, 443-452.

18. Oliveria SA, Ellison RC, Moore LL et al. (1992) Parent-child relationships in nutrient intake: the Framingham Children's Study. Am J Clin Nutr 56, 593-598.

19. Vauthier JM, Lluch A, Lecomte E et al. (1996) Family resemblance in energy and macronutrient intakes: the Stanislas Family Study. Int J Epidemiol 25, 1030-1037.

20. Intersalt Cooperative Research Group (1988) Intersalt: an international study of electrolyte excretion and blood pressure. Results for 24 hour sodium and potassium excretion. BMJ 297, 319-328.

21. Stamler J, Elliot P, Dennis B et al. (2003) INTERMAP: background, aims, design, methods, and descriptive statistics (nondietary). J Hum Hypertens 17, 591-608.

22. Stamler J (1997) The INTERSALT Study: background, methods, findings, and implications. Am J Clin Nutr 65, 2 Suppl., S626-S642

23. World Health Organization (2007) Reducing Salt Intake in Populations. Report of WHO Forum and Technical Meeting, 5-7 October 2006, Paris, France. Geneva: WHO; available at http://www.who.int/dietphysicalactivity/Salt_Report_VC_ april07.pdf

24. DeVon HA, Block ME, Moyle-Wright P et al. (2007) A psychometric toolbox for testing validity and reliability. J Nurs Scholarsh 39, 155-164.

25. DeMayer EM, Lowenstein SW \& Thilly $\mathrm{CH}$ (1979) The Control of Endemic Goitre. Geneva: WHO; available at http://Hatnim.co.kr/new/data/titration.pdf

26. Sandell EB \& Kolthoff IM (1937) Micro determination of iodine by a catalytic method. Mikrochem Acta 1, 9-25.

27. Abuye C \& Berhane Y (2007) The goitre rate, its association with reproductive failure, and the knowledge of iodine deficiency disorders (IDD) among women in Ethiopia: cross-section community based study. BMC Public Health 7, 316 .

28. Bulliyya G, Dwibedi B, Mallick G et al. (2008) Determination of iodine nutrition and community knowledge regarding iodine deficiency disorders in selected tribal blocks of Orissa, India. J Pediatr Endocrinol Metab 21, 79-87.

29. Charlton KE, Gemming L, Yeatman H et al. (2010) Suboptimal iodine status of Australian pregnant women reflects poor knowledge and practices related to iodine nutrition. Nutrition 26, 963-968.

30. Charlton K, Yeatman H, Lucas C et al. (2012) Poor knowledge and practices related to iodine nutrition during pregnancy and lactation in Australian women: pre- and post-iodine fortification. Nutrients 4, 1317-1327. 
31. Mirmiran P, Nazeri P, Amiri P et al. (2013) Iodine nutrition status and knowledge, attitude, and behavior in Tehranian women following 2 decades without public education. J Nutr Educ Behav 45, 412-419.

32. De Vriendt T, Matthys C, Verbeke W et al. (2009) Determinants of nutrition knowledge in young and middle-aged Belgian women and the association with their dietary behaviour. Appetite 52, 788-792.

33. He M, Piche L \& Beynon C et al. (2010) Screenrelated sedentary behaviors: children's and parents' attitudes, motivations, and practices. J Nutr Educ Behav $\mathbf{4 2}$, $17-25$.

34. Stenhammar C, Sarkadi A \& Edlund B (2007) The role of parents' educational background in healthy lifestyle practices and attitudes of their 6-year-old children. Public Health Nutr 10, 1305-1313.

35. McLeod ER, Campbell KJ \& Hesketh KD (2011) Nutrition knowledge: a mediator between socioeconomic position and diet quality in Australian first-time mothers. J Am Diet Assoc 111, 696-704.

36. Vereecken CA, Keukelier E \& Maes L (2004) Influence of mother's educational level on food parenting practices and food habits of young children. Appetite 43, 93-103.

37. Aranceta J, Perez-Rodrigo C, Ribas L et al. (2003) Sociodemographic and lifestyle determinants of food patterns in Spanish children and adolescents: the enKid study. Eur J Clin Nutr 57, Suppl. 1, S40-S44.

38. Inglis V, Ball K \& Crawford D (2005) Why do women of low socioeconomic status have poorer dietary behaviours than women of higher socioeconomic status? A qualitative exploration. Appetite 45, 334-343.

39. Klesges RC, Stein RJ, Eck LH et al. (1991) Parental influence on food selection in young children and its relationships to childhood obesity. Am J Clin Nutr 53, 859-864.

40. Ategbo EA, Sankar R, Schultink W et al. (2008) An assessment of progress toward universal salt iodization in Rajasthan, India, using iodine nutrition indicators in school-aged children and pregnant women from the same households. Asia Pac J Clin Nutr 17, 56-62.

41. Valeix P, Faure P, Peneau S et al. (2009) Lifestyle factors related to iodine intakes in French adults. Public Health Nutr 12, 2428-2437.

42. Azizi F, Mehran L, Sheikholeslam R et al. (2008) Sustainability of a well-monitored salt iodization program in Iran: marked reduction in goiter prevalence and eventual normalization of urinary iodine concentrations without alteration in iodine content of salt. J Endocrinol Invest 31, 422-431.

43. Beard T (2008) Iodised salt damages two campaigns. Lancet 371, 471-472.

44. Mattes RD (1997) The taste for salt in humans. Am J Clin Nutr 65, 2 Suppl., 692S-697S.

45. Rasanen M, Niinikoski H, Keskinen S et al. (2003) Parental nutrition knowledge and nutrient intake in an atherosclerosis prevention project: the impact of child-targeted nutrition counselling. Appetite 41, 69-77.

46. Vejbjerg P, Knudsen N, Perrild H et al. (2009) Estimation of iodine intake from various urinary iodine measurements in population studies. Thyroid 19, 1281-1286. 